\title{
Latest advances in innate antiviral defence
}

\section{Aaron Irving and Bryan RG Williams*}

\author{
Address: Monash Institute of Medical Research, Monash University, Monash Medical Centre, 246 Clayton Road, Clayton, Victoria 3168, Australia \\ *Corresponding author: Bryan RG Williams (bryan.williams@med.monash.edu.au) \\ FI000 Biology Reports 2009, I:22 (doi: 10.3410/BI-22)
}

The electronic version of this article is the complete one and can be found at: http://FI000.com/Reports/Biology/content/I/22

\begin{abstract}
Recent identification of key components in the pattern recognition receptor pathway of retinoic acidinducible gene- I-like receptors, coupled with the characterisation of a new cytoplasmic DNA-sensing molecule, has led to a greater understanding of the role that viral nucleic acids play in activating innate immunity. This activation of type-I interferon is essential for both limiting viral infection and stimulating activation of the adaptive immune response.
\end{abstract}

\section{Introduction and context}

Upon gaining access to a cell, a virus is recognised by the innate immune response of the host, predominantly through the presence of foreign nucleic acids binding to pattern recognition receptors (PRRs). Key effectors of this response are Toll-like receptors (TLRs) and retinoic acidinducible gene-1 (RIG-I)-like receptors (RLRs), which act by triggering signalling cascades, ultimately resulting in the production of type-I interferons (IFNs), the corresponding interferon-stimulated genes (ISGs), and activation of other key regulators of innate immunity, such as nuclear factor-kappa-B (NF- $\kappa \mathrm{B})$. This initial response is essential to limit viral infection and activate natural killer cells and dendritic cells, setting in train the adaptive immune response. While much has been learned about TLR signalling pathways, the mechanism by which RLRs lead to IFN activation has yet to be fully elucidated. The recent independent discovery by different groups of a key regulator named MPYS, stimulator of interferon genes (STING), or MITA has now identified a critical component of the pathway linking RLRs to type-I IFN production $[1,2]$. Moreover, other studies have revealed a key component in the mechanism of DNA-dependent activation of the IFN regulatory factors (IRFs) [3].

RIG-I, melanoma differentiation-associated gene 5 (MDA5), and laboratory of genetics and physiology 2 (LGP2) are a small family of RNA helicases residing in the cytoplasm that contain RNA-binding domains capable of recognising foreign viral transcripts, such as those from negative-strand RNA viruses [4]. Whereas all three helicases function similarly, they differ in sizespecific and sequence motif-specific recognition of viral transcripts [5,6]. RIG-I also contains a self-regulatory domain that recognises 5 -triphosphorylated singlestranded or double-stranded RNA to allow activation [7]. This affects the ability of each helicase to activate the innate immune system in response to different pathogens. The activation occurs through the tandem CARD (caspase recruitment domain) in RIG-I and MDA5, which binds to the mitochondrial antiviral signalling protein (MAVS/IPS-1/CARDIF/VISA) [8-11]. Once activated, MAVS triggers activation of two protein complexes [TANK-binding kinase 1 (TBK1)-I $\kappa$ B kinase epsilon (IKK $\varepsilon$ )-IKK $\gamma$-TANK (TRAF family member-associated NF- $\kappa \mathrm{B}$ activator) and IKK $\alpha-\mathrm{IKK} \beta-\mathrm{IKK} \gamma]$ involved in activation of the IRFs and the NF- $\kappa \mathrm{B}$ transcription factor, respectively (Figure 1).

\section{Major recent advances}

Two research groups have independently identified a transmembrane protein, residing in both the endoplasmic reticulum and mitochondrial membrane, which is necessary for RIG-I-mediated IFN activation $[1,2]$. While differences in localisation were reported in the two papers, it was proposed that STING interacted with a RIG-I-SSR2/TRAP $\beta$ translocon complex, facilitating a link between viral RNA transcripts and IFN activation. Zhong 
Figure I. Cytoplasmic recognition of viral nucleic acids

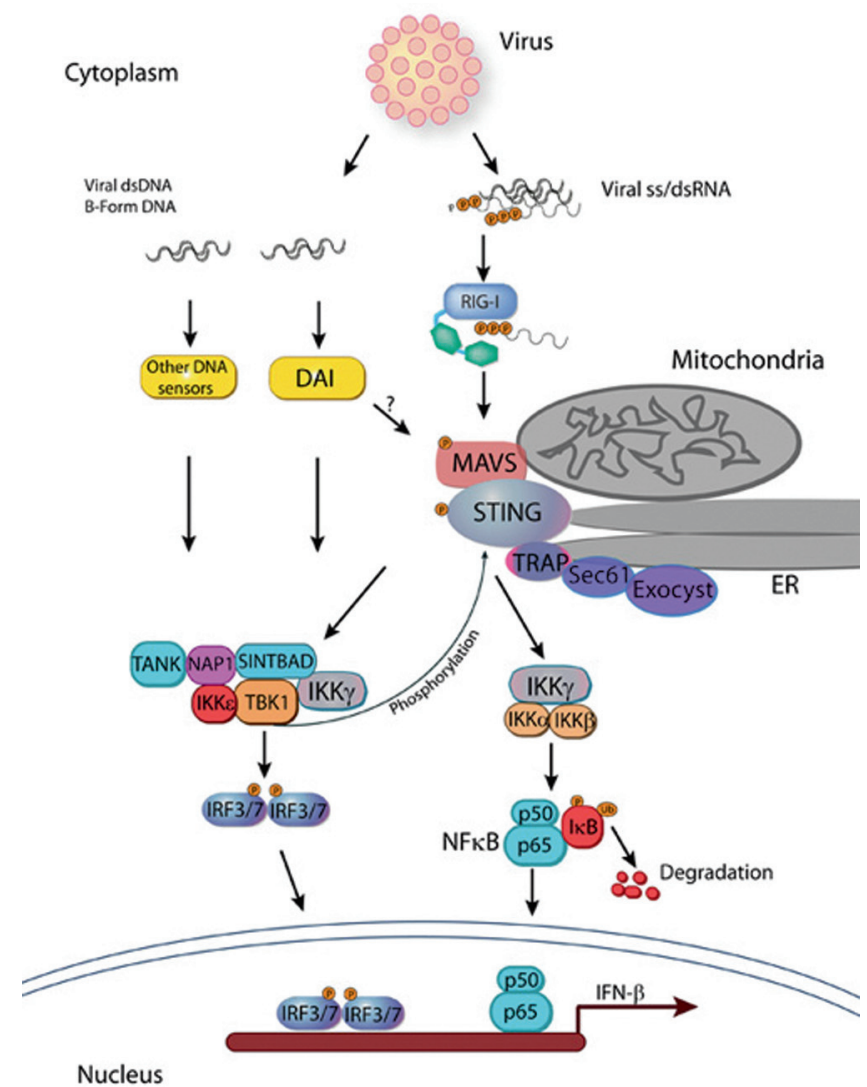

Stimulation of DAI and possibly other DNA sensors by viral dsDNA (or B-form DNA) activates the TANK-NAPI-SINTBAD-IKK $\gamma$-IKK $\varepsilon$-TBKI kinase complex and stimulates phosphorylation of IRF3 and probably IRF7. This process could explain the function of STING/MITA/MPYS in DNA sensing. Viral ss/dsRNA recognition through RIG-I-MAVS interaction requires STING and the TRAP-Sec6I-Exocyst complex to stimulate the same kinase complex as DNA sensing and also activates the IKK $\gamma-\mathrm{IKK} \alpha-\mathrm{IKK} \beta$ complex to trigger NF- $\kappa$ B activation. DAI, DNA-dependent activator of interferon regulatory factor; ds, double-stranded; ER, endoplasmic reticulum; IFN- $\beta$, interferon (type I)-beta; IKK, I $\kappa$ B kinase; IRF, interferon regulatory factor; MAVS, mitochondrial antiviral signalling protein; NAPI, nuclear factor-kappa-B-activating kinase-associated protein I; NF- $\kappa$ B, nuclear factorkappa-B; P, phosphate; RIG-I, retinoic acid-inducible gene-I; SINTBAD, similar to nuclear factor-kappa-B-activating kinase-associated protein I TANK (TRAF family member-associated nuclear factor-kappa-B activator)binding kinase I adaptor; ss, single-stranded; STING, stimulator of interferon genes; TANK, TRAF family member-associated nuclear factor-kappa-B activator; TBKI, TANK (TRAF family member-associated nuclear factorkappa-B activator)-binding kinase I; TRAP, translocon-associated protein.

et al. [2] also showed a link for STING in RIG-I signalling, through MAVS, and its interaction with TBK1/IRF3. STING is encoded by the identical gene previously named MPYS, a plasma membrane tetraspanner implicated in mitochondrial and surface membrane presentation of antigens through an interaction with major histocompatibility complex type II [12]. However, an unequivocal role for this molecule has been shown in pathogen-associated molecular pattern recognition through the use of knockout mice. In mice deficient in STING or in cells derived from these mice, IRF3 activation via TBK1 is compromised and an increased susceptibility to viral infections is evident. However, there also appears to be a cell-type dependency of STING for production of a complete IFN response to viral RNA. Despite differences in the predicted mechanism of action, one via MAVS and the other via the translocon complex, both groups also showed an additional role for STING in non-CpG DNA-mediated induction of type-I IFNs.

In addition to activating an RNA-sensing mechanism, virus DNA can induce a protective innate immune response through other cellular sensors. This recognition was believed to be through the action of TLR9 recognising CpG-rich DNA $[13,14]$. However, there is also evidence indicating a TLR9-independent activator of ISGs [15]. Recent work has revealed DNA-dependent activator of interferon regulatory factors DAI/DLM-1/ ZBP1 as a key component in the recognition of DNA through its three DNA-binding domains. DNA binding by DAI activates dimer formation enabling interaction with TBK1 and IRF3, enhancing activation of IRF3 and possibly IRF7 in response to foreign cytoplasmic DNA. This interaction is dependent upon DNA to maintain the interaction of DAI with TBK1 [16].

Interestingly, the ability of DAI to induce IRF activation in response to pathogenic or host DNA residing in the cytoplasm is cell type-dependent [16]. In mouse embryonic fibroblasts with depleted DAI, there was only a minimal reduction to non-CpG (B form)mediated DNA induction of DNA. This, along with previous evidence, suggests that other DNA-sensing molecules required for recognition of DNA present in the cytoplasm remain to be identified. Nonetheless, reduction of DAI in the macrophage cell lines showed a decrease in IFN induction upon viral infection.

The characterisation of further components in the RLR signalling pathway has identified an important link between cytoplasmic RNA sensors and the TBK1/IRF protein complex for activation of IFN. The DNA cytoplasmic sensor, DAI, also interacts with TBK1/IRF. This major component of IFN induction plays a role in both RNA and DNA cytoplasmic sensing and emphasises a convergence of two different PRR pathways. 
Important to note is the abundance of viral proteins aimed at inhibiting either RLR sensing (for example, influenza virus NS1 $[17,18]$ and human metapneumovirus $G$ protein [19]) or DNA sensing, inhibited by Vaccinia virus E3L [20] and porcine circovirus type 2 [21]. Different viral proteins have also evolved to target the convergence of the two pathways and inhibit TBK1 and IRF3 phosphorylation. These include Ebola virus VP35 [22], Herpes simplex virus $1 \gamma 34.5$ [23], rabies virus P protein [24], and hantavirus G1 [25], among many others (reviewed in [26]).

\section{Future directions}

These recent findings provide new insights into the signalling pathways triggered by viral nucleic acids but still leave many unanswered questions. The exact mechanism of action for STING/MITA remains to be determined, along with its localisation and role in either MAVS activation or the translocon complex. The latter raises questions about the way viral nucleic acids are processed and presented to activate the innate immune response of the cell.

Further investigation should lead to the identification of other cytoplasmic DNA sensors and elucidate which sensors are required in each cellular compartment or cell type. This will provide a better understanding of host response to different pathogens and of the particular cell type engaged by the host to recognise the infection. Careful characterisation of all components required for recognising cellular pathogens will lead to a greater understanding of the innate immune response and ideally provide new therapeutic targets to help treat infections.

\section{Abbreviations}

DAI, DNA-dependent activator of interferon regulatory factor; IFN, interferon (type I); IKK, I $\kappa \mathrm{B}$ kinase; IRF, interferon regulatory factor; ISG, interferon-stimulated gene; MAVS, mitochondrial antiviral signalling protein; MDA5, melanoma differentiation-associated gene 5; NF$\kappa \mathrm{B}$, nuclear factor-kappa-B; PRR, pattern recognition receptor; RIG-I, retinoic acid-inducible gene-1; RLR, retinoic acid-inducible gene-1-like receptor; STING, stimulator of interferon genes; TANK, TRAF family member-associated nuclear factor-kappa-B activator; TBK1, TANK (TRAF family member-associated nuclear factor-kappa-B activator)-binding kinase 1; TLR, Toll-like receptor.

\section{Competing interests}

The authors declare that they have no competing interests.

\section{Acknowledgements}

Work in the authors' laboratory is supported by grants from the US National Institutes of Health (P01 CA062220 and R01 AI034039) and the Australian National Health and Medical Research Council (436814).

\section{References}

I. Ishikawa $H$, Barber GN: STING is an endoplasmic reticulum adaptor that facilitates innate immune signalling. Nature 2008, 455:674-8.

FI000 Factor 9.9 Exceptional

Evaluated by Bryan Williams 8 Sep 2008, Michael Gale 9 Sep 2008, Grant McFadden 10 Oct 2008, Adolfo Garcia-Sastre 13 Oct 2008

2. Zhong B, Yang Y, Li S, Wang YY, Li Y, Diao F, Lei C, He X, Zhang L, Tien $\mathrm{P}$, Shu HB: The adaptor protein MITA links virus-sensing receptors to IRF3 transcription factor activation. Immunity 2008, 29:538-50.

FI000 Factor 6.0 Must Read

Evaluated by Grant McFadden 24 Oct 2008

3. Takaoka A, Wang Z, Choi MK, Yanai H, Negishi H, Ban T, Lu Y, Miyagishi M, Kodama T, Honda K, Ohba Y, Taniguchi T: DAI (DLMI/ZBPI) is a cytosolic DNA sensor and an activator of innate immune response. Nature 2007, 448:50I-5.

FI000 Factor 6.5 Must Read

Evaluated by Alan Houghton 2 Aug 2007, Grant McFadden 3 Aug 2007, David Underhill 7 Aug 2007

4. Yoneyama M, Kikuchi M, Natsukawa $T$, Shinobu N, Imaizumi $T$, Miyagishi M, Taira K, Akira S, Fujita T: The RNA helicase RIG-I has an essential function in double-stranded RNA-induced innate antiviral responses. Nat Immunol 2004, 5:730-7.

FI000 Factor 8.0 Exceptional

Evaluated by Grant McFadden 2 Jul 2004, Caetano Reis e Sousa 14 Jul 2004

5. Kato H, Takeuchi O, Mikamo-Satoh E, Hirai R, Kawai T, Matsushita K, Hiiragi A, Dermody TS, Fujita T, Akira S: Length-dependent recognition of double-stranded ribonucleic acids by retinoic acid-inducible gene-I and melanoma differentiation-associated gene 5. J Exp Med 2008, 205:160I-10.

FI000 Factor 3.0 Recommended

Evaluated by Caetano Reis e Sousa

6. Saito T, Owen DM, Jiang F, Marcotrigiano J, Gale M Jr.: Innate immunity induced by composition-dependent RIG-I recognition of hepatitis C virus RNA. Nature 2008, 454:523-7.

FI000 Factor 4.8 Must Read

Evaluated by Bryan Williams 17 Jun 2008, Grant McFadden 30 Jul 2008

7. Takahasi K, Yoneyama M, Nishihori T, Hirai R, Kumeta H, Narita R, Gale M Jr., Inagaki F, Fujita T: Nonself RNA-sensing mechanism of RIG-I helicase and activation of antiviral immune responses. Mol Cell 2008, 29:428-40.

8. Kawai T, Takahashi K, Sato S, Coban C, Kumar H, Kato H, Ishii KJ, Takeuchi O, Akira S: IPS-I, an adaptor triggering RIG-I- and Mda5-mediated type I interferon induction. Nat Immunol 2005, 6:981-8.

9. Meylan E, Curran J, Hofmann K, Moradpour D, Binder M, Bartenschlager R, Tschopp J: Cardif is an adaptor protein in the RIG-I antiviral pathway and is targeted by hepatitis $\mathbf{C}$ virus. Nature 2005, 437: I 167-72.

FI000 Factor 8.0 Exceptional

Evaluated by Astar Winoto 29 Sep 2005, Eckhard Podack 2 Dec 2005 
10. Seth RB, Sun L, Ea CK, Chen Z]: Identification and characterization of MAVS, a mitochondrial antiviral signaling protein that activates NF-kappaB and IRF 3. Cell 2005, I 22:669-82.

FI000 Factor 9.8 Exceptional

Evaluated by David Wallach 6 Sep 2005, John Kyriakis 28 Sep 2005, Jenny Ting II Nov 2005

II. Xu LG, Wang YY, Han KJ, Li LY, Zhai Z, Shu HB: VISA is an adapter protein required for virus-triggered IFN-beta signaling. Mol Cell 2005, 19:727-40.

12. Jin L, Waterman PM, Jonscher KR, Short CM, Reisdorph NA, Cambier JC: MPYS, a novel membrane tetraspanner, is associated with major histocompatibility complex class II and mediates transduction of apoptotic signals. Mol Cell Biol 2008, 28:50 I4-26.

I3. Ishii Y, Yamaguchi K; Meropenem Surveillance Group: Evaluation of the susceptibility trends to meropenem in a nationwide collection of clinical isolates in Japan: a longitudinal analysis from 2002 to 2006. Diagn Microbiol Infect Dis 2008, 6 I:346-50.

14. Krieg AM, Yi AK, Matson S, Waldschmidt TJ, Bishop GA, Teasdale R, Koretzky GA, Klinman DM: CpG motifs in bacterial DNA trigger direct B-cell activation. Nature 1995, 374:546-9.

15. Ishii KJ, Coban C, Kato H, Takahashi K, Torii Y, Takeshita F, Ludwig H, Sutter G, Suzuki K, Hemmi H, Sato S, Yamamoto M, Uematsu S, Kawai T, Takeuchi O, Akira S: A Toll-like receptor-independent antiviral response induced by double-stranded B-form DNA. Nat Immunol 2006, 7:40-8.

FI000 Factor Exceptional

Evaluated by Caetano Reis e Sousa 23 Nov 2005, Grant McFadden 24 Jan 2006

16. Wang Z, Choi MK, Ban T, Yanai H, Negishi H, Lu Y, Tamura T, Takaoka A, Nishikura K, Taniguchi T: Regulation of innate immune responses by DAI (DLM-I/ZBPI) and other DNAsensing molecules. Proc Natl Acad Sci U S A 2008, 105:5477-82.

FI000 Factor 6.0 Must Read

Evaluated by Grant McFadden 9 Apr 2008

17. Min JY, Krug RM: The primary function of RNA binding by the influenza A virus NSI protein in infected cells: inhibiting the $\mathbf{2}^{\prime}$-5' oligo (A) synthetase/RNase L pathway. Proc Natl Acad Sci U S A 2006, 103:7100-5.

18. Pichlmair A, Schulz O, Tan CP, Naslund TI, Liljestrom P, Weber F, Reis e Sousa C: RIG-I-mediated antiviral responses to single- stranded RNA bearing 5'-phosphates. Science 2006, 314:997-100|.

FI000 Factor 8.3 Exceptional

Evalauted by Jurg Tschopp 27 Oct 2006, Patrick S. Moore 21 Nov 2006, Clifford Harding 24 Nov 2006, Rino Rappuoli 28 Nov 2006

19. Biacchesi S, Skiadopoulos MH, Yang L, Lamirande EW, Tran KC, Murphy BR, Collins PL, Buchholz UJ: Recombinant human Metapneumovirus lacking the small hydrophobic $\mathrm{SH}$ and/or attachment $\mathbf{G}$ glycoprotein: deletion of $\mathbf{G}$ yields a promising vaccine candidate. J Virol 2004, 78: I2877-87.

20. Smith EJ, Marie I, Prakash A, Garcia-Sastre A, Levy DE: IRF3 and IRF7 phosphorylation in virus-infected cells does not require double-stranded RNA-dependent protein kinase $\mathbf{R}$ or Ikappa B kinase but is blocked by Vaccinia virus E3L protein. J Biol Chem 200I, 276:895I-7.

21. Wikstrom FH, Meehan BM, Berg M, Timmusk S, Elving J, Fuxler L, Magnusson M, Allan GM, McNeilly F, Fossum C: Structuredependent modulation of alpha interferon production by porcine circovirus 2 oligodeoxyribonucleotide and CpG DNAs in porcine peripheral blood mononuclear cells. J Virol 2007, $81: 4919-27$.

22. Cardenas WB, Loo YM, Gale M Jr., Hartman AL, Kimberlin CR, Martinez-Sobrido L, Saphire EO, Basler CF: Ebola virus VP35 protein binds double-stranded RNA and inhibits alpha/beta interferon production induced by RIG-I signaling. J Virol 2006, 80:5168-78.

23. Verpooten D, Ma Y, Hou S, Yan Z, He B: Control of TANKbinding kinase I mediated signaling by the gammal34.5 protein of herpes simplex virus I. J Biol Chem 2009, 284: 1097-105.

24. Brzozka K, Finke S, Conzelmann KK: Identification of the rabies virus alpha/beta interferon antagonist: phosphoprotein $\mathbf{P}$ interferes with phosphorylation of interferon regulatory factor 3. J Virol 2005, 79:7673-8I.

25. Alff PJ, Gavrilovskaya IN, Gorbunova E, Endriss K, Chong Y, Geimonen E, Sen N, Reich NC, Mackow ER: The pathogenic NY-I hantavirus G I cytoplasmic tail inhibits RIG-I- and TBKI-directed interferon responses. J Virol 2006, 80:9676-86.

26. Bowie AG, Unterholzner L: Viral evasion and subversion of pattern-recognition receptor signalling. Nat Rev Immunol 2008, 8:91।-22. 